\title{
NUEVOS ESPACIOS FEMENINOS EN LA NARRATIVA EGIPCIA ACTUAL: REEM BASSIOUNEY
}

\section{NEW FEMININE SPACES IN TODAY'S EGYPTIAN FICTION: REEM BASSIOUNEY}

\author{
María José Rebollo Ávalos
}

Author / Autora:

María José Rebollo Ávalos

Universidad de Extremadura

Cáceres, Spain

rebollo@unex.es

https://orcid.org/0000-0001-5590-2835

Submitted / Recibido: 22/03/2021

Accepted / Aceptado: 01/09/2021

To cite this article / Para citar este artículo: Rebollo Ávalos, M. J. (2022). Nuevos espacios femeninos en la narrativa egipcia actual: Reem Bassiouney. Feminismo/s, 39, 241-265. https://doi.org/10.14198/ fem.2022.39.09

\section{Licence / Licencia:}

This work is licensed under a Creative Commons Attribution 4.0 International.

\section{(c) (i)}

(C) María José Rebollo Ávalos

\section{Resumen}

En el siglo XXI, la narrativa femenina egipcia es una literatura crítica con el orden social imperante. El tema medular suele ser la ralentización del proceso de cambio social a causa de la presión ejercida por el sistema tradicional dominante. En este artículo abordaremos cómo la escritora egipcia Reem Bassiouney (Alejandría, 1973), en su novela Profesora Haná, proyecta una imagen de la mujer árabe actual fuera de los moldes tradicionales en busca de un espacio propio. En este contexto, los conflictos sociales, personales y de género están en la base de personajes frustrados, inseguros y aislados ante la inmutabilidad de la situación o ante la debilidad o el fracaso para provocar un cambio. El objetivo es mostrar que la literatura es utilizada por la escritora árabe como una herramienta para concienciar sobre los problemas actuales. Al igual que otras escritoras árabes, recurre a la ficción literaria para abordar las relaciones de género y la actitud de hombres y mujeres en el marco de una sociedad tradicionalmente androcéntrica que le asigna a cada uno un papel concreto en un espacio definido. Bassiouney utiliza el sarcasmo, la ironía y el humor como armas contra una sociedad que dificulta la integración de 
algunos de sus individuos por su comportamiento y aspiraciones. Se constata también que la autora egipcia se inscribe en la nueva generación de autores que no procuran la presentación de su entorno de una forma realista, sino que se sirven de sus vivencias y recuerdos para construir el escenario de su hastío ante lo que les rodea. Como resultado se confirma que, a través de la literatura, la mujer árabe actual reclama un espacio propio para hacer visible su situación y para acceder al espacio público generando opinión.

Palabras clave: literatura árabe femenina; crítica social; Reem Bassiouney; mujeres y sociedad egipcia actual; relaciones de género.

\begin{abstract}
In the 21 st century, the Egyptian women fiction is a critical review of the prevailing social order. The core topic is usually the slowdown in the process of social change because of the pressure exerted by the traditional dominant system. In this article we will address how the Egyptian writer, Reem Bassiouney (Alexandria, 1973), in her novel Professor Hana, projects an image of today's Arab woman in search of her own space and out of traditional roles. In this context, social, personal and gender conflicts create frustrated, insecure, and isolated characters, regarding the immutability of the situation or the weakness or failure to bring about change. The aim is to show that literature is used by this Arab writer as a tool to raise awareness of current problems. Like some other Arab women writers, she uses literary fiction to approach gender relations as well as the attitudes of men and women within a traditionally androcentric society which assigns each of them a particular role in a specific space. Bassiouney uses sarcasm, irony and humour as weapons against a society which hinders the integration of some of its individuals because of their behaviour and aspirations. It is also clear that the Egyptian author belongs to the new generation of authors who do not attempt to present their environment in a realistic manner, but they rather use their experiences and memories to construct the scenario of their weariness with their surroundings. As a result, it is confirmed that, through literature, today Arab women are claiming a space of their own to make their situation visible and to gain access to the public framework by generating opinion.
\end{abstract}

Keywords: Arab women's fiction; social criticism; Reem Bassiouney; women and today's Egyptian society; gender relations.

Feminismo/s 39, January 2022, 241-265 


\section{IDENTIDAD FEMINISTA EN LA NARRATIVA DE AUTORAS EGIPCIAS}

Heredera de la crítica social y política de la literatura árabe del siglo XX, la narrativa femenina egipcia del siglo XXI reproduce especialmente la realidad en la que vive la mujer árabe en su escenario cotidiano, en el que despliega su actividad profesional y establece relaciones personales y familiares. Desde una perspectiva de género, la mujer se coloca frente al hombre, pero no siempre en perpetua oposición, y también frente a otras mujeres, a veces en colisión directa, como si se situara ante un espejo que no devuelve su reflejo nítido, con la intención de reafirmar una identidad propia, fuera de los moldes tradicionales y no vinculada indefectiblemente a la figura masculina. En ese intento, sigue la línea de la crítica feminista de autoafirmación y defensa frente a una realidad hostil que suscita frustración, inseguridad, soledad y rechazo, y utiliza la literatura como un canal de expresión individual que fluye hacia la conciencia colectiva a través del lector. Converge así con la literatura femenina contemporánea en la que, como aduce Suárez (2009):

Las autoras, y la comunidad lectora con ellas, ponen de relieve las incongruencias cotidianas y los fallos lógicos de opiniones admitidas secularmente como válidas por mor de la fuerza de la costumbre, ridiculizan las situaciones estereotipadas por medio de la ironía y la sátira, subvierten tabúes convertidos ya en éticos y morales (como la maternidad y la virginidad) y dicotomías inherentes en el lenguaje patriarcal y ampliamente denunciadas por la crítica feminista, y buscan concienciar a los usuarios «inconscientes» que perpetúan a diario esta absurda situación. (pp. 558-559)

Estos asuntos son tratados por las autoras que integran la denominada «generación de los noventa», que engloba a una nueva ola de escritores cuya obra, en opinión del destacado crítico egipcio Hafez (2010): «constitutes a radical departure from established norms and offers a series of sharp insights into arab culture and society» (p. 48). Esta «nueva novela» se vertebra en torno a personajes solitarios, individuales, cercados por hipocresías, convencionalismos y prejuicios que no les identifican y que les impiden evolucionar y sentirse libres a pesar de los reiterados intentos, hecho que les genera impotencia. Es el reflejo de una situación real y de una percepción subjetiva 
que recurre a la ficción literaria, en muchos casos con visos autobiográficos, para denunciar su frustración personal a través de protagonistas engullidos por una sociedad que se revela tradicional e inmutable, e inmersos en un escenario insatisfactorio, en una «realidad deteriorada y rota» (Abdulatif, 2020, p. 47) que rechazan y en un sistema social que dificulta su integración.

Las escritoras árabes en el siglo XXI articulan sus escritos alrededor de un tema medular: la ralentización del proceso de cambio social por la creciente presión que ejerce el sistema tradicional dominante (Tresilian, 2009, p. 61), en el que el régimen patriarcal, como un referente de la identidad árabe-islámica, se ha visto fortalecido en los últimos años por condicionantes religiosos apoyados desde el estamento político y enraizado en la estructura social. En este sentido, la arabista Del Amo (1997) compendiaba así la amplitud de los temas abordados por las escritoras árabes hasta finales del siglo XX, motivos que se reproducen en la corriente temática de la literatura actual:

Descripción de su propio conflicto en la búsqueda de su identidad como mujeres; su conflicto con los hombres y de los hombres con su entorno y, por último, su conflicto con las normas de la sociedad tradicional y el de la sociedad con su devenir histórico. (pp. 23-24)

Por lo expuesto hasta ahora, resulta interesante rastrear en la escritura árabe contemporánea cómo las autoras, muy preparadas intelectualmente dentro y fuera de sus fronteras geográficas, plantean en sus obras las relaciones de género y la posición de hombres y mujeres en el marco de una sociedad opresora, en la que se ven forzados a representar un papel determinado en función de su sexo. Salirse de la pauta fijada supone sufrir el rechazo y pagar un precio a nivel profesional y/o personal. Esta literatura critica que el orden social se perpetúa por la acción de grupos religiosos y por políticas gubernamentales, e incluso por las propias mujeres responsables de la educación de sus hijos y, por supuesto, por los hombres, beneficiarios principales.

La última generación de escritoras se mira a sí misma, observa su entorno e intenta proyectar una imagen de la mujer árabe actual que se conforma fuera de los paradigmas tradicionales. Desde el relato novelado o a través del ensayo, la poesía y la obra dramática las autoras árabes del siglo XXI no pretenden simplemente distraer al lector, ni sus escritos van dirigidos en exclusiva a un público femenino, sino que se abren a la sociedad árabe en 
general, y a través de la traducción o directamente en inglés o francés, en ocasiones de un modo muy particular, hacia el lector occidental. Su literatura es un discurso que condena la desigualdad, que hace cimbrear los durables binomios tradición/modernidad, Oriente/Occidente, público/privado, para reprobar unos códigos sociales que se mantienen inalterables.

Desde los planteamientos de la crítica literaria feminista, se sirven de la literatura como vehículo de circulación de ideas, estableciendo un estrecho vínculo entre el autor y el lector para crear nuevas perspectivas de la realidad que les rodea, de modo que la literatura no es meramente un acto de comunicación, sino también de conocimiento de otras experiencias (Moreno, 1994, p. 108). Este binomio autor/lector es definido de manera nítida por el escritor y traductor egipcio Abdulatif (2020): «Escribir una obra literaria tiene el objetivo de llegar a un significado que es la visión del mundo según su autor, y leer una obra literaria es comprender e interpretar esta visión» (pp. 37-38).

\section{PROFESORA HANÁ, NOVELA DE REEM BASSIOUNEY, Y LA VISIÓN DE LA MUJER EN ENTORNO ÁRABE}

\subsection{Aproximación biobibliográfica a la autora. La relevancia de los personajes femeninos.}

En este estudio focalizamos el tema en la autora egipcia Reem Bassiouney, utilizando como referencia la obra al-Duktūra Hanā' (Profesora Haná, 2008), editada también en inglés y en griego y hasta el momento su único trabajo traducido al español ${ }^{1}$, sumándose así a un reducido pero importante número de volúmenes árabes que son accesibles al lector de habla hispana (Comendador y Fernández, 2006; López Enamorado, 2003). Esta novelista no es de las más conocidas de la citada generación y su obra tampoco ha sido demasiado abordada por la crítica, pero se vincula a los parámetros temáticos y estéticos de la nueva narrativa egipcia: novelas y relatos con crítica social mordaz y con atisbos de un humor punzante, a través de un protagonista aislado y finalmente derrotado. Aborda la narración como una aparente

1. Los datos bibliográficos de todas las obras de esta autora, citadas en el texto, se pueden consultar en la lista de referencias incluida al final del artículo. 
ficción autobiográfica, donde intervienen personajes frustrados ante la inmutabilidad del escenario o ante la debilidad y el fracaso para provocar un cambio. Reem Bassiouney, en consonancia con autoras precedentes, aborda la existencia de fronteras morales, reforzadas por muros psicológicos, que las estructuras sociales imperantes custodian celosamente para cegar el más mínimo resquicio capaz de quebrar dichos límites y amenazar con demoler los parámetros de comportamiento delimitados para ambos sexos (Herrero, 2012, pp. 140-141). Traspasar ese baluarte tiene siempre sus consecuencias; en el caso de la protagonista, Haná, su soberbia, considerada una actitud inapropiada y no tolerada en una mujer, es la causa de su propia destrucción, porque el fracaso de su «desmedida» ambición la conduce a un paroxismo de desesperanza que propicia el derrumbe de su propia identidad.

Reem Bassiouney nació en Alejandría en 1973 y forma parte de una nueva estirpe de mujeres árabes preparadas académicamente y que desarrollan su actividad literaria en el siglo XXI. En 1994 se gradúa con honores en Lengua y Literatura Inglesa en la Universidad de Alejandría y al año siguiente realiza un postgrado en Lingüística en la misma Universidad. Continúa sus estudios en Oxford y en 2002 obtiene un doctorado en Sociolingüística. Poco después se traslada a Estados Unidos, donde ha sido profesora de Lingüística y de Literatura en las Universidades de Utah y Georgetown. En el año 2013 regresa a Egipto y actualmente es profesora de Sociolingüística en el Departamento de Lingüísticas Aplicadas de la Universidad Americana de El Cairo. Ha publicado en inglés diversos estudios sobre Lingüística y Sociolingüística, compaginando sus trabajos científicos con su producción literaria. Desde 1995 ha incluido varios relatos cortos en el semanario literario egipcio Ajbār al-Adab, creado en 1993 por el destacado y prolífico escritor Gamal al-Ghitani, encarcelado en los años 60 por sus críticas al régimen de Nasser y galardonado con varios premios literarios².

Hasta el momento, Reem Bassiouney ha publicado siete novelas, todas ellas escritas en árabe, la última de las cuales ha sido editada a finales del

2. Los datos personales y profesionales de la autora se han consultado en diferentes páginas web, de donde se han recogido también algunas entrevistas en diferentes medios de comunicación egipcios y extranjeros. Para la información académica hemos recurrido a su currículum en la página web de la Universidad Americana de El Cairo.

Feminismo/s 39, January 2022, 241-265 
2018, Awlād an-nās, y está ambientada en el Egipto de los mamelucos. El título alude al nombre por el que eran conocidos los hijos de los mamelucos que habían nacido en Egipto. Se trata de una trilogía compendiada en un solo volumen que narra tres historias cuyo punto en común es la gran mezquita-madrasa del Sultán Hassan en El Cairo. Como ella misma y otros autores árabes y especialmente egipcios han plasmado en sus narraciones, recurre al pasado para explicar o cuestionar el presente (Del Amo, 2014, pp. 273-274), pero en esta ocasión la autora aporta nuevos puntos de vista sobre la identidad egipcia, basándose fundamentalmente en el aspecto humano, en las experiencias vitales. Como es habitual en su producción, destaca un personaje femenino, en esta ocasión Zeynab, símbolo de la mujer egipcia fuerte, decidida y valiente.

Bassiouney publicó su primer relato en 2005, Rä'ihat al-baḥr (El olor del mar). En él, a través de su protagonista, Rania, ofrece una visión franca y crítica de la sociedad egipcia, asunto que será reiterativo en el resto de su producción. Su reconocimiento le llegó dos años después con la novela $B \bar{a}{ }^{\prime}{ }^{6}$ al-fustuq (El vendedor de pistachos) que obtuvo en 2009 el premio Middle East Literature in Translation. Esta novela es una historia de amor y de búsqueda de identidad ambientada en la clase media urbana egipcia. Gira en torno a un triángulo amoroso entre la protagonista, la joven Wafá, de fuertes creencias religiosas y arraigada a la tradición, que se enamora de su primo Ashraf, un joven consentido, educado en Inglaterra y que, por un revés económico, acaba como emigrante pobre en Estados Unidos. El tercer vértice es Lubna, una periodista liberal y combativa que anhela una reforma social y que contrasta con el personaje femenino principal. A lo largo de los trece años que transcurren en la novela, desde 1980 hasta 1993, los personajes se cuestionan sus convicciones y su situación, hecho del que emana una crítica política y social hacia el Egipto del momento.

Con su tercera incursión en la literatura, al-Duktūra Hanā' (La profesora Haná, 2008), consiguió en 2009 el prestigioso galardón literario egipcio que desde 2005 otorga la Sawiris Foundation for Social Development. Dicha Fundación le concedió el Primer Premio para Jóvenes Escritores en la categoría de Novela. En esta ocasión, la protagonista es una mujer de clase acomodada, soltera e independiente, de 40 años, profesora de universidad, celosa de sus sentimientos y con ambiciones personales y profesionales. El comienzo 
de la novela resulta sorprendente, pues aborda uno de los temas tabú de la literatura árabe: Haná desea celebrar su cuarenta cumpleaños perdiendo su virginidad y su elección como partenaire es un joven alumno, Jáled, del barrio pobre de Bulak, con el que finalmente se casará en secreto. Tras esta catarsis inicial, la novela no se centra únicamente en la consideración de la mujer soltera e independiente en la sociedad egipcia, sino en las relaciones de género dentro de los encorsetados parámetros sociales.

Un año después, en al-Hubb 'alà-l-tarīqa-l-'arabiyya (El amor al estilo árabe) despliega un discurso feminista, social y político para abordar la construcción de la identidad árabe y de su diversidad a través de personajes de distinta procedencia en la diáspora. La autora utiliza su formación en Sociolingüística para reflejar esa diversidad a través del uso de los dialectos sirio, palestino, iraquí, jordano y, por supuesto, egipcio. La trama gira en torno a la protagonista femenina Safá, una joven musulmana egipcia recién graduada en derecho y su historia de amor con Nabil, un hombre de negocios libanés, musulmán chií, a quien conoce en Estados Unidos.

En 2010 publica $A \check{s} y \bar{a}$ ' $r a \bar{\prime} i$ ' $a$ (Cosas maravillosas) en la que la autora sigue resistiéndose a plegarse a una realidad que no le satisface. En esta ocasión aborda la disolución moral de los individuos de todas las clases sociales, la difícil relación entre sus miembros y la corrupción política, temas recurrentes en sus trabajos. Y lo hace a través del romance entre dos personajes atrapados por su condición social, por diferencias culturales y por la desigualdad de género. La protagonista es Asmá, una madre soltera pobre que lucha por conseguir una vida mejor para sus hijos.

Su penúltimo trabajo, Muršid siyāḥ̂̀ (Guía turístico, 2017), fue presentado en la Feria Internacional del Libro de El Cairo en su cuadragésima novena edición celebrada del 27 de enero al 10 de febrero de 2018. Según la autora, es su novela más compleja y ha tardado varios años en escribirla, pues empezó a gestarla pocos meses después de su vuelta a Egipto. La trama se desarrolla en torno a un guía turístico de Lúxor que se relaciona con visitantes extranjeros y nacionales, lo que le sirve para profundizar en las relaciones entre Oriente y Occidente. Se centra en conceptos e ideas estereotipados o conformados a través de la información generada desde Occidente, forjados para configurar una visión concreta de Oriente, de su glorioso pasado, pero también de la 
situación actual en torno a una cuestión principal que transciende en todas sus novelas, la identidad árabe.

Reem Bassiouney mira hacia la mujer árabe y a su sociedad con la visión doble de quien comparte y conoce ambas culturas, la oriental y la occidental. En sus trabajos, la autora no fomenta antagonismos preconcebidos que enfrentan y particularizan, sino que presenta esas discrepancias culturales como reclamos para la búsqueda de la identidad femenina en entorno árabe, en el que se revelan perfiles compartidos en ambas sociedades. En general, en los relatos de esta y de otras autoras coetáneas la mujer no es un personaje comparsa, sino la figura central.

Relacionado con el tema de nuestro interés, esta autora ha construido personajes femeninos (Rania, Wafá, Haná, Safá, Asmá y Zeynab) que se revelan como mujeres independientes y fuertes, pero que se ven rodeadas, $e$ incluso acosadas, por tradiciones culturales y presiones sociales que acentúan las diferencias con la mujer occidental según el imaginario general. Así sucede particularmente con Haná, la protagonista de su tercera novela y nuestro referente en este artículo, una mujer liberada y autoritaria en una sociedad patriarcal y tradicional que está subyugada por el elemento masculino personal y profesionalmente. Haná figura a esa mujer que se tambalea en la eterna lucha entre la tradición y el fracaso de la modernidad, pero presentada ahora con un nuevo viso. Se ciñe a la definición que la periodista franco-tunecina Bessis (2008) hace de la mujer árabe:

Las mujeres de estas latitudes parecen, de hecho, oscilar entre las diferentes versiones del modernismo sin modernidad, que no ha sabido ni querido librarlas por completo de las antiguas opresiones, y el redescubrimiento de identidades construidas sobre la obsesión por controlarlas. (p. 19)

La literatura femenina árabe hoy no pretende reflejar meramente la disparidad entre el hombre y la mujer en una sociedad tradicionalmente androcéntrica. Las protagonistas de sus escritos suelen ser mujeres que se mueven en la sociedad actual y que batallan en una lucha perseverante para alcanzar nuevas conquistas ${ }^{3}$. Son conscientes de la dificultad de la empresa, asediada

3. La evolución, aunque a diferente ritmo, que se ha producido en el entorno árabe desde el Magrib hasta el Mašriq, especialmente en la primera década del siglo XXI, y que supone pasos importantes hacia el fin de los modelos tradicionales que imperan en

Feminismo/s 39, January 2022, 241-265 
por un aumento de la represión femenina a tenor del auge del islamismo y de la vuelta a factores religiosos conservadores, más radicales en unos países que en otros. Tras la Primavera Árabe, lejos de asentar logros, se han radicalizado posturas ancladas en la sumisión de la mujer como marca de la identidad árabe islámica y signo de su fortaleza. Sin embargo, aspiran al compromiso de la comunidad árabe, cuyos miembros, más allá de su sexo, deben «modernizar» y hacer progresar a la sociedad. La presión es sufrida en especial por quienes no acatan o se ciñen al papel que estos fortalecidos radicalismos les imponen.

Sobre todo, las mujeres sufren la opresión de una sociedad en fase regresiva, que las excluye y veta cuando desean adoptar un rol diferente en la sociedad y en la familia ${ }^{4}$. La protagonista de la novela Profesora Haná vive en un estado de anomia social y por eso reclama su identidad dentro de una sociedad que le permite acceder al espacio público, pero cuyas alarmas se encienden si traspasa los límites y amenaza el orden imperante. En consecuencia, manifiesta su crítica hacia unas pautas de conducta perpetuas y recurre a la condena explícita, al sarcasmo, a la ironía y al humor como armas punzantes contra una sociedad que dificulta la integración de algunos de sus individuos por su comportamiento y aspiraciones. El determinismo biológico que se impone a la mujer oriental, y la supedita a la necesidad, casi obligación, de tener un hombre al que servir, atender y obedecer, está presente en varios pasajes de la obra. La autora, a través de su protagonista femenina, se rebela contra esta tradicional postura, asumida por muchas de sus compatriotas, y apostilla con ironía: «Sí. Necesitaba una buena ración

estos países, relacionados fundamentalmente con la emancipación de la mujer y la relación entre los sexos, es abordado por Bessis y Martín Muñoz (2010).

4. La arabista Gema Martín Muñoz (2010, 22 de diciembre) incide en el hecho de que desde hace cinco décadas las mujeres son parte activa en la esfera pública en los cambios demográficos, sociales y económicos que se han producido en el mundo árabe, a ritmos distintos según el entorno, pero que se enfrentan a las barreras impuestas por sistemas políticos sólidamente asentados y reacios a transformar los modelos tradicionales que afectan especialmente a la población femenina. Una situación que se arrastra hasta hoy.

Feminismo/s 39, January 2022, 241-265 
de dulce miel para quedarse pegada a su sitio para siempre» (2013, p. 199; 2015, p. 229) $)^{5}$.

Ella y las compañeras de generación han continuado la estela de sus predecesoras desde finales del siglo XIX y todo el siglo $\mathrm{XX}^{6}$, escritoras que prepararon el camino para que la mujer árabe, que había accedido a la educación, utilizara el periodismo y la literatura como vías para hacer visible su situación y acceder al espacio público generando opinión. En este sentido, Ashour et al. (2009) aducen: «These writers boldly chose two outlets: journalism, which gave immediate access to the reading public and allowed them to shape public opinion, and novel, the most malleable literary genre and the newcomer to Arabic culture» (p. 13).

Reem Bassiouney pertenece a esta nueva generación de jóvenes escritoras árabes, formadas en universidades nacionales y extranjeras e inmersas en el mundo global, que no temen expresarse sin rémora y libremente sobres temas tabú ${ }^{7}$, y señalar los abusos políticos y la represión social que, por causas económicas, sociales y culturales, se sufren en los países árabes en distinto grado. Su compatriota la escritora egipcia Mansoura Ez-Eldin manifestaba en una entrevista:

Muchos escritores modernos, entre ellos yo, escribimos desde una situación no alineada, con el objeto de ver el mundo y la sociedad que nos rodea de una manera más neutra, lejos de afiliaciones a un movimiento concreto que pueda nublar la mente, la vista o el pensamiento, con ansias de una apertura a la cultura mundial. (el-Ashry, 2010, p. 163)

5. Las citas textuales de la obra objeto de nuestro estudio que aparecen a lo largo del artículo se han extraído de la edición en español (Bassiouney, 2013); a continuación, se cita también la página correspondiente en la edición en árabe que hemos manejado (Bassiouney, 2015). En las referencias siguientes solo aparecerá el número de página de cada edición en ese orden.

6. La referencia bibliográfica más importante de la literatura árabe escrita por mujeres, por la completa nómina de autoras recogida en ella, ha sido elaborada por Ashour et al. (2008).

7. Su coetánea, la escritora Miral al-Tahawi (2010), reflexiona sobre cómo abordan las escritoras árabes los temas tabú y las prohibiciones sociales. 


\subsection{La protagonista, mujer entre el empoderamiento y la opresión}

Volviendo a la obra de referencia, Profesora Haná, señalamos que es una novela de extensión media dividida en diez capítulos y narrada en tercera persona, que ofrece una visión introspectiva del personaje central. Se aprecian características de esa nueva narrativa egipcia de la que habla el citado crítico Hafez (2010, p. 49), como el protagonismo concedido a personajes aislados a causa de rancios estereotipos. Haná es una mujer angustiada, sola y que sufre el rechazo del resto de las mujeres, con las que no se identifica. En un momento del relato, Layla, la hermana de Haná le espeta:

¿Qué clase de mujer eres? ¿Es que puede haber una mujer a la que no le guste el chocolate? Hermanita, los dulces son los que dan la vida. La mujer que no come dulces permanece en un vacío emocional, y tú bastante tienes con el vacío en el que vives. Un poco de chocolate nos ayuda en los días amargos. Cuando llegues a mi edad lo comprenderás. Hay momentos en la vida de una mujer en que sólo el azúcar y los dulces la reconfortan. (p. 75; p. 82)

Es frecuente a lo largo del relato la referencia a los dulces, que funcionan en sentido literal y metafórico. En este último se vinculan a la idea de llevar una vida agradable, ajena a cualquier conflicto o amargura. Por ello la protagonista se rebela y grita «nací para mandar, no para comer pastelillos» (p. 136; p. 155). El gusto árabe por los dulces, una costumbre impresa también en el carácter egipcio, es en la narración un símbolo de la sumisión a las tradiciones. Haná odia los dulces como un rechazo a las pautas de conducta imperantes. No será hasta el final de la novela cuando claudica y regresará a su casa junto a Jáled, que ha comprado una bandeja de dulces y expresa su deseo de comer con ella baklawa, lo que comporta la sumisión a las normas establecidas.

La narración se construye como una ficción autobiográfica pues, aunque no narra una trayectoria personal, es posible atisbar en ella experiencias vitales de la autora. La protagonista es de una edad un poco mayor que ella, se mueve en el entorno universitario y es profesora de literatura, especialidad en la que Bassiouney se graduó. En una entrevista que concede a la BBC World (Brown, 2011), en la que con la excusa de hablar sobre esta obra expone sus opiniones sobre la literatura femenina en Egipto, confirma tajantemente que Haná, su personaje, no es ella, pero es posible inferir en sus páginas 
referencias a diferentes paradigmas de mujeres árabes de hoy, y ella es una de esas mujeres. Se puede ver aquí su vínculo con el juicio de Moreno (1994) en torno a la irrelevancia en esta literatura de la constatación de realismo:

No importa si este mundo recreado en la literatura es una ficción «realista» o completamente inventada; de lo que se trata es de recuperar los aspectos simbólicos que se despliegan en el aspecto distorsionante de la novela, el relato, el drama o el poema. (p. 108)

A través de la lectura y por las palabras de la propia autora, se constata que Profesora Haná no es en sí una novela realista, sino que utiliza la realidad; tampoco es en puridad una obra autobiográfica, sino que se articula como una ficción en la que la autora recurre a sus propias experiencias, al tiempo que, a través de personajes de distinto sexo y condición social y cultural, plantea diferentes posturas y reacciones ante las mismas circunstancias en un escenario único, El Cairo. La autora se dirige al lector, no para ser reconocida en el texto, sino para que reaccione ante lo que lee. De este modo, la actitud de cada uno de los personajes ayuda a configurar desde distintos puntos de vista la realidad egipcia, con especial incidencia en la marginación social.

En este sentido, la autora egipcia se inscribe en la nueva generación de autores que no procuran la presentación de su entorno de una forma realista, sino que se sirven de sus vivencias y recuerdos para construir el escenario de su hastío ante lo que les rodea. La arabista López Enamorado (2000) recogía en uno de sus artículos las palabras de Muntașir al-Qaffāš sobre las nuevas formas narrativas egipcias: «un verdadero interés por parte del autor hacia lo que le rodea, así como hacia las ideas, sensaciones y sentimientos que se elaboran en su interior de los que no puede desprenderse ni cargar con ellos» (p. 305). De este modo introducen al lector en la novela, provocándole reaccionar, conscientes de que la recepción de esa provocación es muy distinta, por cuestiones culturales y de género, en cada uno de ellos. Se trata, por tanto, de una literatura osada que puede sorprender en Occidente y trastornar en Oriente.

La protagonista de la obra es una mujer soltera y una reputada profesora de universidad en El Cairo que, a pesar de su independencia económica y de su éxito profesional, se siente acosada por su entorno social, contra el que se rebela abierta y públicamente, aunque sin obtener el resultado deseado y de 
ahí el conflicto. En cierto momento, cuando cree que controla su vida personal y profesional y se enfrenta orgullosa a los convencionalismos sociales, grita eufórica, «iQué placer es que la mujer rija y gobierne su propio destino!» (p. 102; p. 114). Este espejismo se plasma definitivamente al final del relato, hasta convertirse en un sueño imposible, ante la constatación del fracaso del intento de cambiar la sociedad y la certeza de la pérdida personal, profesional y sentimental. Derrotada, Haná reconoce con amargura y casi vencida que no le queda nada: «Nada, salvo la molesta sensación de sentirse mujer que él había despertado en su interior» (p. 199; p. 229).

\subsection{El valor simbólico de los espacios}

No suele haber una mención expresa al tiempo, ni la obra se estructura de acuerdo con una secuencia cronológica concreta, pues la acción va desarrollándose a partir de las acciones de personajes resignados, desesperanzados, aislados, que se revelan frustrados ante la inmutabilidad de la situación. Nada cambia, por lo que el transcurrir del tiempo no es importante. En cambio, los espacios sí son significativos, pues especialmente la universidad y la casa familiar condicionan la actitud del personaje principal. Son lugares cerrados que determinan el cambio de comportamiento radical de la protagonista. Mientras en la universidad Haná «sentía que rebosaba de vitalidad; el poder la embriagaba. Se veía capaz de cualquier cosa» (p. 116; p. 133), en contraposición, en su casa respiraba «el aroma a historia, muerte y soledad» (p. 159; p. 183). Ambos son espacios simbólicos, una metáfora de Egipto, país que en apariencia quiere romper con atávicas tradiciones pero que finalmente rechaza los cambios.

Haná es un personaje aislado, porque se encuentra atrapado; su casa es su refugio, pero también su prisión. Es la antigua morada familiar en el acomodado barrio cairota de Zamalek y permanecía tal y como sus padres la habían dejado, a pesar del tiempo transcurrido desde su muerte. En un isomorfismo simbólico, la casa es como Egipto, familiar, cercana, propia, pero también inalterada, en la que todo sigue pasando de acuerdo con unas pautas precisas que subrayan su aislamiento frente al resto de la sociedad. Esa constante provoca seguridad, pero también un temor que se proyecta en el profundo desasosiego que muchas veces asedia a la protagonista: «Había 
noches largas en las que una nube densa envolvía su cuerpo helado y la despertaba, sin dejarla descansar, y la negra oscuridad la estrangulaba sin llegar nunca a matarla» (p. 33; p. 33). Se acentúan los visos simbólicos, e incluso la función de la casa como cronotopo bajtiniano, cuando se vincula casa y sociedad egipcia. El estatismo de Egipto se sentencia con rotundidad en la frase, «¿Quién se atrevía a soñar en un país que había descubierto el arte de embalsamar y se sentía bien orgulloso de ello?» (p. 204; p. 235).

La actitud de la protagonista cambia radicalmente en la universidad: «su voz sonaba siempre más poderosa y desafiante cuando estaba sentada en su mesa: era casi otra persona distinta» (p. 113; p. 129). En este espacio, ella ejerce su autoridad, es la directora del departamento y esto la hace sentirse poderosa porque tiene la capacidad de imponer cambios, pero al final se siente igualmente rechazada. Leemos:

Porque te empeñabas en destruir un sistema que lleva funcionando millones de años, desde la época de Ramsés. Un sistema en el que todos estamos educados. Querías cambiarlo en un año. ¿Me entiendes ahora? Querías que floreciera la justicia y la igualdad, y eso es imposible. Intenté explicarte una y otra vez que, en lugar de cambiar el sistema, era preferible que echaras una mano a quien necesitara tu ayuda. Somos un país al que le encanta la corrupción, presumir, los chanchullos, beneficiar a familiares y amigos, y tú no lo quieres entender. Y al final te has hecho daño a ti misma y a los desgraciados que te rodean. (p. 205; pp. 236-237)

La universidad es un trasunto de la falsa modernización que Egipto quiere transmitir, pero en la que se reproducen todos los vicios sociales y políticos que han caracterizado a esta sociedad y a su política durante años: corrupción, sumisión al poder, doble moral, diferencia de clases, supremacía masculina.

Las escasas ocasiones en las que la secuencia narrativa se enmarca en espacios abiertos recrean estas mismas actitudes simbólicas. En una salida al campo con los alumnos de la universidad, la autora incide en la soledad y el aislamiento de la protagonista, que se mantiene ajena a lo que ocurre a su alrededor mientras lee un libro debajo de un árbol sobre una manta cuidadosamente colocada en el suelo a modo de barrera, marcando un espacio propio, privado, infranqueable para el resto de personajes. A pesar de ser un 
espacio abierto, se ponen barreras y se traslada la atmósfera asfixiante que se percibe en la casa, en definitiva, en el país.

En el capítulo final, la profesora Haná, traicionada por su amante-marido, rechazada por sus compañeros, despojada de su puesto de mando, sale a la calle y, acompañada únicamente por el frío de la noche, se sienta en un banco desde donde contempla el curso ininterrumpido del Nilo, al que odiaba: «Se sentó ante el río. Parecía helado, sereno, profundo. No le gustaba nada su frialdad ni su profundidad» (p. 199; p. 229). Junto a ella pasan transeúntes que también parecen descontentos, hastiados, y el río, como símbolo de la vida que transcurre (vita flumen), del tiempo que pasa inexorable, no interrumpe su curso, ajeno a la frustración, a la soledad, a la derrota de la mujer. Entonces ella es consciente de que nada se detendrá, nada cambiará. He aquí otro elemento simbólico en una novela aparentemente directa que, sin embargo, posee un trasfondo significativo.

\subsection{Las relaciones de género}

Profesora Haná aborda también la difícil relación entre los individuos en la sociedad árabe actual, en la que hombres y mujeres viven sin tener conocimiento mutuo. La protagonista se interroga: «¿Qué sabía de los hombres? [...] ¿Qué preocupaba a los hombres en Egipto? ¿Tenían miedo de las mujeres? ¿Qué les asustaba de ellas?» (p. 19; p. 16). Por su parte, los hombres ven a todas las mujeres como personas simples, débiles de carácter, porque lo contrario las hace peligrosas para ellos y desdichadas para ellas, «iQué peligrosa es la mujer a la que uno no consigue comprender!» (p. 187; p. 214).

Estos estereotipos convierten en víctimas de la presión social a quienes osen transgredir las normas por las que cada individuo está considerado según la posición y actitud que tradicionalmente se le asigna. Las escritoras árabes hablan sobre la mujer y también, de modo colateral, sobre la presión que sufren los hombres si no se ajustan al prototipo árabe forjado a través de condicionamientos políticos, religiosos y culturales, y como consecuencia de ello se convierten en otras víctimas del juicio del resto de la sociedad.

Jáled, el protagonista masculino, vive una contradicción interna distinta a la del personaje femenino, pero provocada por la misma circunstancia. Ella se muestra públicamente como una mujer valiente, capaz de enfrentarse 
orgullosa a los convencionalismos sociales, mientras que él teme el juicio social y tan solo en su psique y en la intimidad de su relación con Haná se permite expresar su deseo de que las cosas cambien. Cuando en un ataque de rabia y autoafirmación de control de sí misma y sobre los demás, Haná confiesa a la madre de Jáled el matrimonio secreto con su hijo, este acto de rebelión a las normas establecidas supone el cuestionamiento de la posición del hombre, porque ella es mayor que él, es la directora de su departamento, de otra clase social y no puede darle hijos. Ahora es él quien se somete a la censura social:

Por primera vez era él quien se sentaba en el banquillo de los acusados. Se vería expuesto a una presión psicológica terrible. Su hermana tomaría el mando para vengarse de él y pondría en peligro su autoridad. Se sentiría prisionero de los deseos de todos los que lo rodeaban, de sus opiniones. Su madre se sentiría desorientada, lo había perdido, la había traicionado, la había...

La profesora Haná le había asestado un golpe bajo fatal.

Ella pensaba que los derechos de la mujer en Egipto eran sistemáticamente pisoteados. Pero ¿qué pasaba con el hombre? ¿Qué había de la tortura y de las abominables coerciones psicológicas de todo tipo a las que él se vería sometido ahora, las amenazas, las coacciones, los reproches, la petición de responsabilidades? (pp. 137-138; pp. 157-158)

Desde Occidente, abordar la idea del hombre árabe como víctima no parece un planteamiento aceptable, en cuanto a que prevalece la idea de que la mujer está subyugada a la voluntad masculina. Haná solía repetir inútilmente a sus alumnos: «Los hombres de nuestro país necesitarían cirugía para eliminar sus excesos, sus ideas retrógradas, esa educación equivocada» (p. 41; p. 42). En la literatura femenina de este siglo no es extraordinario encontrarse con alegatos que defienden al hombre árabe como ser humano libre para expresar sus sentimientos y para sentirse vulnerable sin traicionar su identidad, porque actuar siempre según lo esperado también subyuga al hombre. En esta obra de la doctora Bassiouney es un motivo secundario, pero hay otras autoras, como Joumana Haddad (2014), que lo han elevado a axial.

El victimismo masculino no es manifestado por el hombre, porque sería hacer pública la debilidad, «cualidad» que tradicionalmente se asocia como inherente a la mujer y determinada en ella biológicamente, y aún 
no desarraigada de ciertos comportamientos sociales. Haná reacciona con contundencia ante la reiterativa identificación de la debilidad con la esencia de la mujer:

Sabía que la debilidad era una de las cualidades más conocidas de las mujeres. El problema es que ella nunca había sido débil y que ningún hombre se había atrevido a desvirgarla. El hombre quiere la victoria, y la mujer la derrota; pero ella odiaba la derrota y la debilidad. (p. 27; p. 26)

Haná se enfrenta a los demás, pero también a sí misma y esto provoca en ella un desasosiego vital constante: «La confundían sus emociones contradictorias. Culpa, pasión y vergüenza por ser mujer y a la vez seguridad, fortaleza y la sensación de que podía obtener todo lo que quisiera» (p. 80; p. 89). Estos desajustes y sentimientos enfrentados son percibidos por el personaje como un elemento más de su inadaptación social.

En algunas fases de la narración la autora presenta a la profesora Haná semejante a una heroína árabe de la literatura oral (Vidal, 2005), con actitudes y comportamientos tradicionalmente masculinos (decisión, autoridad, ambición), poniendo de relieve la existencia, en la sociedad árabe actual en particular, de conflictos en las relaciones de género cuando la mujer excede y se sale de su papel de esposa y madre. Pero es contradictorio su deseo de sentir, actuar y amar como una mujer, sin que ese afán sea concebido como síntoma de debilidad. Por un lado, odia ser mujer y, por otro, anhela ser como cualquier otra, casarse, tener hijos y casi lamenta haber dedicado su vida a alcanzar metas que en realidad no le han permitido integrarse en la sociedad. Se pregunta: «ipor qué había desperdiciado su vida entre trabajo, estudio, miedo y un amor imposible?» (p. 19; p. 16).

Esa situación de alienación social se refleja en pensamientos obsesivos que le provocan temor e inquietud, y de los que difícilmente puede desprenderse. Se manifiestan tanto en sus pautas de conducta (es una mujer metódica y maniática), como en su guerra interior de sentimientos y aptitudes enfrentados. Así, cuando su esposo secreto la abraza en la intimidad de su vieja casa familiar, «sentía como sus brazos la rodeaban, la amenazaban, la confortaban, le daban miedo» (p. 94; p. 106).

Haná, representante de una mujer árabe real pero todavía atípica para el lector occidental, es el centro del relato. Las escritoras del siglo XXI evitan en sus escritos conceder el protagonismo a la mujer tradicional, con una actitud 
sumisa que la sigue definiendo por antonomasia. Se niegan a encerrarla en el entorno de la vida privada sin ningún papel destacado en la vida pública. Las mismas escritoras son ejemplo de una nueva mujer, pues como defiende la controvertida escritora libanesa Haddad (2011), hay 'otra' mujer árabe: «la atípica, la rebelde, independiente, moderna, abierta, poco convencional, muy bien educada y autosuficiente» (p. 29). Ambas conviven en las sociedades árabes actuales y en ocasiones el nuevo tipo de mujer se debate en una constante dinámica de defensa y crítica sobre su propia situación. Haddad (2011) confirma que «tenemos el don de ser nuestro propio y más terrible enemigo» (p. 29). La literatura agrieta y destruye los clichés tradicionales y permite abogar por una sociedad en la que hombres y mujeres compartan un mismo papel modernizador.

Bassiouney denuncia que en muchas ocasiones se usa a la mujer para transmitir una falsa imagen de modernidad y progreso: «Colocar a una mujer en la dirección del departamento era una señal inequívoca de que Egipto era un país avanzado que no discrimina entre hombres y mujeres en función de los puestos de trabajo o de sus competencias» (p. 47; p. 49). Se reprueba una situación que se mantiene desde la época poscolonial en países como Egipto, donde la causa de las mujeres ha sido utilizada políticamente por los regímenes autoritarios, con el fin de suavizar su imagen de cara al exterior y presentarse como una sociedad moderna en la que la mujer instruida tiene cabida y participa activamente en la vida pública (Ketiti, 2017, pp. 73-76). La rivalidad entre las profesoras Maysa y Haná para ocupar la dirección del departamento es clave para abordar que la modernización de Egipto pasa por que las mujeres desempeñen un papel activo en ese proceso, pero esconde y manifiesta al mismo tiempo que la consideración del prestigio que una mujer merece está supeditado a valores tradicionales con leves concesiones. La euforia inicial ante el hecho de que una mujer ocupe el cargo académico revela su auténtico rostro cuando se describe a cada una de las candidatas. Maysa representa el ideal de mujer egipcia, casada, pendiente de su marido y de sus hijos, lleva hiyab y había cumplido con la peregrinación a La Meca; es de trato fácil y agradable, querida y apreciada por todos, pues sabía estar en su sitio y comportarse adecuadamente. En cambio, Haná, a pesar de su prestigio internacional, era una mujer difícil, autoritaria, soltera, segura de sí misma, desafiante en su trato con los demás, egoísta, tozuda, ambiciosa,

Feminismo/s 39, January 2022, 241-265 
incluso tiránica, demasiado franca y orgullosa. En definitiva, Haná representa lo que la sociedad árabe no acepta ni admite en una mujer, y a pesar de todo es elegida directora y desde ese momento, el resto de personajes, masculinos y femeninos, desea y espera ver su caída.

Los comentarios masculinos hacia Haná giran en torno a su actitud orgullosa y en que no acepta su condición femenina según los parámetros de esta sociedad. Las siguientes frases son ilustrativas al respecto: «Una mujer con carácter, pero desdichada» (p. 29; p. 29); «Tú misma eres un problema. Eres un enorme camión. Nadie puede controlarte» (p. 35; p. 35); «Siempre de mal humor y violenta con los hombres, ¿quién la va a aguantar?» (p. 83; p. 92); «¿Por qué no se comporta como una mujer? ¿Qué pasa? ¿Va a perder su fuerza porque un solo día se comporte como una mujer» (p. 87; p. 97); «Haná nunca ha sido fácil de tratar y de comprender» (p. 187; p. 214).

Resulta significativa la actitud hacia ella de las mujeres tradicionales, para quienes Haná supone una amenaza. Confirman la alienación social que sufre el personaje y la falta de la denominada por la crítica feminista «sororidad», sobre todo en torno a un asunto incuestionablemente femenino, engendrar hijos. Maysa, su compañera y rival en la Universidad, ataca: «Sí Haná; puede que seas la directora del departamento, pero no dejas de ser una solterona, sin hijos ni esposo» (p. 78; p. 86). En el otro extremo de la escala social y cultural está la madre de Jáled, una mujer de clase humilde, tradicional, servil, obediente y ligada siempre a una figura masculina, primero su padre, luego su marido y ahora su hijo. Ella y su hija Shaimá, una joven estudiante de bachillerato que lleva hiyab y cuyo objetivo es ser esposa y madre, reaccionan con furia ante la noticia del matrimonio secreto de su hijo y hermano respectivamente con esa mujer que no es de su edad ni de su misma clase social e incapaz de darle hijos:

Mamá -habló una animada Shaimá mientras tomaba asiento a su lado-. Su vientre no puede engendrar. ¿No habías dicho tú siempre que cuando una mujer no puede tener hijos el marido tiene derecho a casarse de nuevo? Ahí tienes la razón para hacerlo y seguro que lo hace. (p. 178; p. 206)

Tampoco se verá apoyada por su propia hermana, Layla. Casada con un hombre cruel y autoritario, es repudiada por su marido. Esta traumática separación la lleva a un cambio drástico: se entrega a la religión, hace la peregrinación a La Meca, y entonces alcanza la consideración y el respeto 
del que no gozaba antes. Comienza a vestir el hiyab y a dar clases de religión, «parecía que la religión se había convertido en un arma en manos de la mujer como lo eran el dinero y la educación. Un arma mucho más poderosa e influyente, que daba miedo a los hombres y los refrenaba» (p. 112; p. 126). Layla sentencia, sin conocer el matrimonio secreto de su hermana: «Yo sé por qué Haná no se ha casado. Porque no hay quien la aguante. Es complicada, cicatera y presuntuosa» (p. 73; p. 80).

Ante el rechazo general, Haná sufre una pérdida de identidad, se convierte en alguien extraño, ajena a la realidad que la rodea, que provoca rechazo y desaprobación. Finalmente sucumbe y se siente excluida del sistema, vencida precisamente por aquello que se considera inherente a su condición femenina:

Sin prolegómeno alguno, su debilidad, su feminidad y la constatación de haber sido vencida por sus sentimientos se abatieron sobre ella, tal y como le había advertido su hermana. El miedo a la soledad, a la muerte, a necesitar y no encontrar una mano en la que apoyarse cada día la empujaba a un pozo sin fondo. (p. 182; p. 208)

Fiel a su propósito de retratar la sociedad árabe actual, la autora identifica en cada personaje a los distintos tipos que la conforman. Todos se convierten en seres frustrados, presos en un Egipto estático que unos aceptan resignados y otros toleran. El hastío y el descontento general, enfocado principalmente en los dos protagonistas, se manifiesta al final, porque a pesar de las diferencias que los separan, hay algo que los une: «La falta de confianza en el sistema, la desesperanza, el sarcasmo, la búsqueda de sí mismo» (p. 201; p. 231). Todo ello genera confusión y desesperación, pero la necesidad de cambiar, de transformar su sociedad, de reconocer a sus individuos es una batalla abierta.

\section{CONCLUSIONES}

La opinión de las citadas escritoras árabes del siglo XXI sigue en la línea de muchas de sus predecesoras, en el sentido de que constatan y lamentan el hecho de que la religión, la política y la tradición se hayan erigido como los sólidos baluartes de la defensa y perpetuidad de un sistema social patriarcal que reafirma la identidad árabe y condiciona a sus individuos. Pero, al mismo tiempo, se plasma un hecho que mantiene la supremacía del hombre 
sobre la mujer, pues las propias mujeres, dentro del entorno familiar, siguen educando a sus hijos e hijas fieles al papel que les corresponde según su sexo. La madre de Haná, una dama de alta alcurnia y muy estricta y respetuosa con las tradiciones y el papel de la mujer en el cuidado de los hijos, solía decir a ella y a su hermana: «Las mujeres no hacen nada por su propia voluntad. Pues no la tienen» (p. 105; p. 118). No es muy diferente la actitud de la madre de Jáled, de un nivel social humilde y cuya vida ha transcurrido en el barrio pobre de Bulaq.

La educación dentro de la familia, basada en la igualdad y en la libertad, puede convertirse en la clave para avanzar en el camino del progreso social, y algunas mujeres árabes cultas, independientes, a través de la literatura fundamentalmente, muestran ese anhelo de cambio. La literatura es un acto íntimo y personal, pero de proyección internacional, es el canal a través del cual las escritoras árabes expresan sus opiniones, sus críticas, sus deseos y ambiciones y también sus frustraciones. A través de ella, y a pesar de la censura que muchas han sufrido, no son mujeres veladas, ni sumisas, ni silenciadas. A lo largo del siglo XX, en el Oriente árabe, autoras de reconocido prestigio como las egipcias Latifah al-Zayyat (1923) y Nawal al-Sa'adawi (1931), la siria Ghada al-Samman (1942), las libanesas Layla Baalbaki (1936) y Hanna al-Shaykh (1945) y en el Occidente árabe las marroquíes Fatima Mernissi (1940) y Janata Bennuna (1940), entre otras, rompieron el silencio femenino para desvelar a una mujer árabe que con valentía desafía las reglas. $\mathrm{Su}$ estela ha sido seguida en este siglo por otras autoras que reclaman su espacio en el campo literario y social del mundo árabe actual. Tanto unas como otras han conseguido llegar al lector árabe y también al occidental, a través de una importante labor de traducción, y algunas de ellas han escrito y publicado también en lenguas europeas.

\section{REFERENCIAS BIBLIOGRÁFICAS}

Abdulatif, A. (2020). Lo irreal y lo experimental en «la nueva novela egipcia» y «la luz nueva» y sus vínculos con Borges. Miscelánea de Estudios Árabes y Hebraicos. Sección Árabe-Islam, 69, 33-59. https://doi.org/10.30827/meaharabe.v69i0.1059

al-Tahawi, M. (2010). La evolución de lo prohibido en la literatura árabe femenina. Culturas. Revista digital de análisis y debate sobre Oriente Próximo 
y el Mediterráneo, 7, 151-161. http://revistaculturas.org/wp-content/ uploads/2013/02/La-evoluci\%C3\%B3n-de-lo-prohibido-en-la-literatuara\%C3\%81rabe-femenina.pdf

Ashour R., Ghazoul, F.J. y Reda-Mekdashi, H. (Eds.). (2008). Arab women writers. A critical reference guide (M. McClure, Trad.). The American University Press (original publicado en árabe en 2004, Dākirat li-l-mustaqbal: mawsu'at al-kātiba al-'arabiyya. Nūr). https://doi.org/10.5743/ cairo/9789774161469.001.0001

Ashour, R., Berrada, M., Ghazoul, F., Rachid, A. y McClure, M. (2009). Arab Women Writers. Southwest Review, 94(1), 9-18. http://www.jstor.org/ stable/43472958

Bassiouney, R. (2005). Rä'ihat al-baḥr. Dar al-Bustani.

Bassiouney, R. (2007). Bā'i ‘ al-fustuq. Maktaba al-Madlubi.

Bassiouney, R., (2009). Al-Hubb 'alá țarīqa-l-'arabiyya. Dar al Hilal.

Bassiouney, R. (2010). Al-'Ašya' rā'i 'a. Dar al-Adab.

Bassiouney, R. (2013). Profesora Haná (J.P. Arias, Trad.). Alba Contemporánea. Bassiouney, R. (2015). Al-Duktūra Hanä'. Maktaba al-Madlubi.

Bassiouney, R., (2016). Al-Hubb 'alá țarīqa-l-'arabiyya. (Última edición). Dar Nahda Misr

Bassiouney, R. (2016). Bā'i ' al-fustuq. (Última edición). Dar Nahda Misr.

Bassiouney, R. (2017). Al-'Ašya' rā'i 'a. (Última edición). Dar Nahda Misr.

Bassiouney, R. (2017). Muršid siyāḥī. Riḥlāt fī zawāyā al-ḥaqüqa. Dar Nahda Misr. Bassiouney, R. (2018). Awlād al-Nās: țalāta-l-mamālīk. Dar Nahda Misr.

Bessis, S. (2008). Los árabes, las mujeres y la libertad (F. Peyrou Tubert, Trad.). Alianza Editorial, Colección Alianza Ensayo.

Bessis, S. y Martín Muñoz, G. (Coords.) (2010). Mujer y familia en las sociedades árabes actuales. Edicions Bellaterra.

Brown, A. (2011, 9 de diciembre). Reem Bassiouney's interview with BBC World about her novel Professor Hanaa. BBC Mundo. https://garnetpub.wordpress. com/2011/12/09/reem-bassiouneys-interview-with-bbc-world-about-hernovel-professor-hanaa/

Comendador, M.L. y Fernández G. (2006). Traducciones de literatura árabe al español 2001-2005. Al-Andalus Magreb, 13, 69-77. http://hdl.handle. net/10498/7981

del Amo, M. (1997). Escribir en femenino plural: las mujeres árabes y la literatura. En M. del Amo (Ed.), El imaginario, la referencia y la diferencia: siete 
estudios acerca de la mujer árabe (pp. 13-31). Departamento de Estudios Semíticos de Granada.

del Amo, M. (2014). Novela, ideología e historia en Egipto (1913-2013). Miscelánea de Estudios Árabes y Hebraicos. Sección Árabe-Islam, 63, 265-277. https://revistaseug.ugr.es/index.php/meaharabe/article/view/14218

el-Ashry, M. (2010). Mansoura Ez-Eldin. Entrevista con la escritora egipcia (Nasr Salti, Trad.). Culturas. Revista digital de análisis y debate sobre Oriente Próximo y el Mediterráneo, 7, 162-167. http://revistaculturas.org/wp-content/ uploads/2013/02/Mansoura-Ez-Eldin.-Entrevista-con-la-autora-Egipcia.pdf Haddad, J. (2011). Yo maté a Sherezade. Confesiones de una mujer árabe furiosa (M. Vicens, Trad.). Ed. Debate.

Haddad, J. (2014). Superman es árabe (J. L. Clariond y G. Bucci, Trads.). Ediciones Vaso Roto.

Hafez, S. (2010, july/aug). The New Egyptian Novel. Urban Transformations and Narrative Form. New Left Review, 64, 47-62. https://newleftreview.org/ issues/ii64/articles/sabry-hafez-the-new-egyptian-novel

Herrero Muñoz-Cobo, B. (2012). Estrategias para la construcción de una identidad. Mujer en punto cero De Nawal al-Sa'adawi. Clepsydra: Revista de Estudios de Género y Teoría feminista, 11, 135-145. https://repositorio.unal. edu.co/handle/unal/55311

Ketiti, A. (2017). Feminismo, identidad y religión en el mundo árabe. Clepsydra: Revista de Estudios de Género y Teoría feminista, 16, 65-82. http://hdl.handle. net/10550/65791

López Enamorado, M. D. (2000). Muntașir al-Qaffāš y la nueva narrativa egipcia. Philologia Hispalensis, 14(2), 301-308. https://doi.org/10.12795/PH.2000.v14. i02.25

López Enamorado, M. D. (2003). Memorias del Mediterráneo: un espacio europeo para la nueva literatura árabe. Estudios Filológicos Alemanes, 3, 423-436. Martín Muñoz, G. (22 de diciembre de 2010). La revolución silenciosa de las mujeres árabes. El País. https://elpais.com/diario/2010/12/22/opinion/1292972404_850215.html

Moreno, H. (1 de marzo de 1994). Crítica literaria feminista. Debate Feminista. Crítica y censura, 9, 107-112. https://doi.org/10.22201/ cieg.2594066xe.1994.9.1750 
Suárez Lafuente, M. S. (marzo-abril de 2009). Las mujeres como tema intertextual en la literatura contemporánea. Destiempos. Revista de curiosidad cultural, 19, 556-575.

Tresilian, D. (2009). Tendencias en la literatura árabe contemporánea. Culturas, 5, 5263. http://revistaculturas.org/wp-content/uploads/2013/02/Tendenciasen-la-literatura-\%C3\%Alrabe-contempor\%C3\%Alnea.pdf

Vidal Luengo, A. R. (primavera, 2005). Mujeres excéntricas en la literatura oral: sultanas, hechiceras, 'liberadas'. Cyber Humanitatis, 36, 53-73. https://web. uchile.cl/vignette/cyberhumanitatis/CDA/vida_sub_simple3/0,1250,PRID\%253D16316\%2526SCID\%253D16321\%2526ISID\%253D577,00.html 